\title{
The Axial Directional Course of the Retrohepatic Segment of Inferior Venacava in Tamilnadu Population - A Cadaveric Study
}

\author{
Dr. Rieyaz.H.A ${ }^{1^{*}}$, Dr. Ananda Rani VS ${ }^{2}$, Dr. Ramesh Kumar Subramanian ${ }^{2}$
}

${ }^{1}$ Assistant Professor of Anatomy, CMC, Coimbatore, Tamilnadu, India

${ }^{2}$ Professor of Anatomy, SRMC \&RI, Porur, Chennai, Tamilnadu, India

\author{
DOI: $10.36348 /$ SIJAP.2019.v02i10.005 \\ | Received: 07.10.2019 | Accepted: 15.10.2019 | Published: 21.10.2019 \\ *Corresponding author: Dr. Rieyaz H. A
}

\section{Abstract}

Background: The retrohepatic segment of the inferior venacava lies in the groove on the posterior surface between caudate and the right lobe of the liver and has the hepatic veins opening into it, these openings are known as "Ostia Venae Hepaticae". Aims \& objectives: The aim of the present study is to analyse and interpret the axial direction course and its variations in the retrohepatic segment of inferior venacava in the Tamilnadu population. Material and Methodology: Seventy formalin-fixed adult liver specimens were taken for this study and carried out in the department of anatomy, SRMC \&RI, during the year 2012-2015. To keep the liver in anatomical position to find out the axial direction in the retrohepatic segment of the inferior venacaval groove concerning the longitudinal axis of the liver, it was observed to have vertical, oblique toward left or curved toward left. Observation \& Results: Our observation of the oblique axial direction of the RHIVC was close to the other observations reported by previous authors in Indians. The incidence of the left curve in the present study was close to the results reported by the majority of previous authors. The vertical orientation of RHIVC was similar to the results reported in the existing literature. In the present study in Tamilnadu population $n=70$, axial direction shows $n=18-25.7 \%$, vertical $n=32-45.7 \%$, oblique $n=20-28.5 \%$. Conclusion: To conclude, this study re-emphasizes the vitality of the knowledge of the varied pattern of the retrohepatic segment of inferior vena cava in facilitating an accurate and better-designed road map for the hepatologists, liver transplant surgeons and interventional radiologists.

Keywords: Liver, Hepatic veins, a longitudinal axis, venacaval groove.

Copyright @ 2019: This is an open-access article distributed under the terms of the Creative Commons Attribution license which permits unrestricted use, distribution, and reproduction in any medium for non-commercial use (NonCommercial, or CC-BY-NC) provided the original author and source are credited.

\section{INTRODUCTION}

The retrohepatic segment of inferior vena cava (RHIVC) was extending superiorly from diaphragmatic opening to an inferiorly caudate lobe lower border. The longitudinal axis of the liver concerning its course appears vertical, obliquely or curve to the left [1]. Recent advancement in the field of hepato-vascular surgery and liver transplantation requires better understanding and knowledge of the retrohepatic segment of inferior venacaval axial anatomy [2]. In the literature, variations in this anatomical region are wide which may be attributed to methodological [3] and ethnic differences [4]. Data available from the Tamilnadu population, in general, is scarce. This study describes the anatomical variations and their course of the retrohepatic segment of inferior venacaval axial orientation in a Tamilnadu population.

\section{MATERIAL AND METHODS}

The retrospective observational cadaveric study of the liver and the retrohepatic segment of inferior venacava were studied by standard dissection of seventy formalin-fixed adult liver specimens, irrespective of sexes. This study was carried out at the department of anatomy, SRMC \&RI, during the year 2012-2015. The specimens with gross deformities were excluded from the study. Before the start of this study, we obtained ethical clearance from the Institutional ethics committee, ethical committee clearance number REF: CSP-MED/13/AUG/08/62 of the abovementioned institution. The study was conducted in a stepwise manner. The liver specimen was kept in the anatomical position to measure the vertical axis of the liver. The axial direction of the venacaval groove was observed to have vertical, oblique toward left or curved toward left according to the vertical axis of the liver as shown in Figure1. Observations were noted down in the sheet which was previously prepared. 


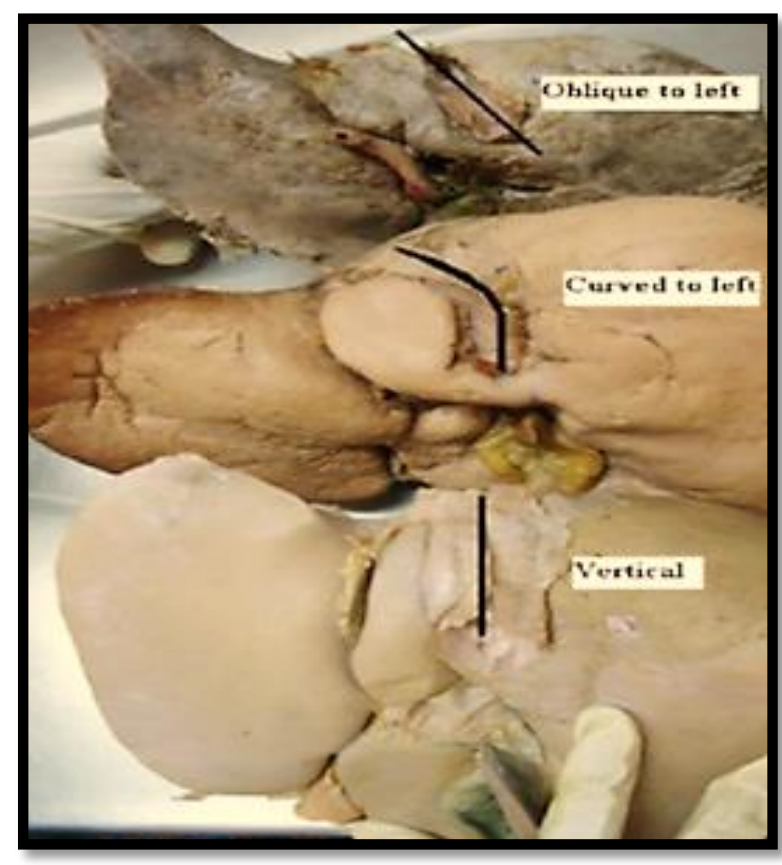

Fig-1: Shows Axial direction - vertical, oblique toward left or curved toward left according to the vertical axis

\section{OBSERVATION \& RESULTS}

In the present study in Tamilnadu population in the year 2012 - 2015, to find out axial directional course in the retrohepatic course of inferior vena cava in 70 cadaveric liver specimens, we observed 18 specimens shows axial direction i.e., 25.7\%, 32 specimens shows oblique direction i.e., $45.7 \%$ and finally 20 specimens shows curved to left i.e., $28.5 \%$. Our observation of the oblique axial direction of the RHIVC was close to the other observations reported by previous authors in Indians. The incidence of the curved to left axial direction in the present study was close to the results reported by the majority of previous authors. The vertical orientation of RHIVC was similar to the results reported in the existing literature.

\section{DISCUSSION}

In the posterior aspect of the liver, there is a groove for venacava in which inferior venacava runs upwards, during its course it forms an axis concerning the vertical axis of the liver [5]. Our study provides data on the axial direction course of the retrohepatic segment of the IVC. Our observation of the oblique axial direction of the RHIVC was close to the observations in Indian's study conducted in the Karnataka population [6]. It was however significantly lower than the values observed among the Northwest population in Indian's [4], Brazilians [7], Thais [8], Kenyans [9] and finally among Indians in Delhi population [10]. The reported incidence of the left curve was not the same in the studies [3, 11]. The vertical orientation of RHIVC was similar to the results reported [13] as shown in Table no $1 \&$ Figure no 2.

Table-1: Shows the comparison measurements of the axial direction of RHIVC in the present vs. past studies in the literature.

\begin{tabular}{|c|c|c|c|c|c|c|}
\hline AUTHOR & $\begin{array}{l}\text { YEAR OF } \\
\text { STUDY }\end{array}$ & POPULATION & $\begin{array}{l}\text { NO OF } \\
\text { LIVERS }\end{array}$ & VERTICAL & OBLIQUE & $\begin{array}{l}\text { CURVED } \\
\text { TO LEFT }\end{array}$ \\
\hline Chang et al. [3] & 1989 & Chinese & 60 & 5 & 10 & 45 \\
\hline Camargo et al. [7] & 1996 & Brazilians & 30 & 4 & 22 & 4 \\
\hline S Imaji\&Rosarin R [8] & 1999 & Thais & 144 & 25 & 110 & 9 \\
\hline Mehran et al. [13] & 2000 & Canadians & 30 & 28 & 2 & 0 \\
\hline Sahni et al. [6] & 2006 & $\begin{array}{l}\text { Northwest Indians } \\
\text { (Chandigarh) }\end{array}$ & 500 & 0 & 332 & 168 \\
\hline $\begin{array}{l}\text { Sagoo\&Agnihotri et } \\
\text { al. [11] }\end{array}$ & 2009 & $\begin{array}{c}\text { Indians } \\
\text { (Punjab) }\end{array}$ & 100 & 8 & 18 & 74 \\
\hline Bundi et al. [9] & 2009 & Kenyans & 80 & 4 & 48 & 28 \\
\hline S.D.Joshi et al. [14] & 2009 & $\begin{array}{c}\text { Indians } \\
\text { (Maharashtra) }\end{array}$ & 69 & 10 & 39 & 20 \\
\hline S K Ghosh et al. [10] & 2012 & $\begin{array}{c}\text { Indians } \\
\text { (Delhi) }\end{array}$ & 160 & 3 & 148 & 9 \\
\hline Veena VS et al. [6] & 2014 & $\begin{array}{c}\text { Indians } \\
\text { (Karnataka) }\end{array}$ & 45 & 11 & 23 & 11 \\
\hline Present Study & 2014 & $\begin{array}{c}\text { Indians } \\
\text { (Tamilnadu) }\end{array}$ & 70 & 18 & 32 & 20 \\
\hline
\end{tabular}




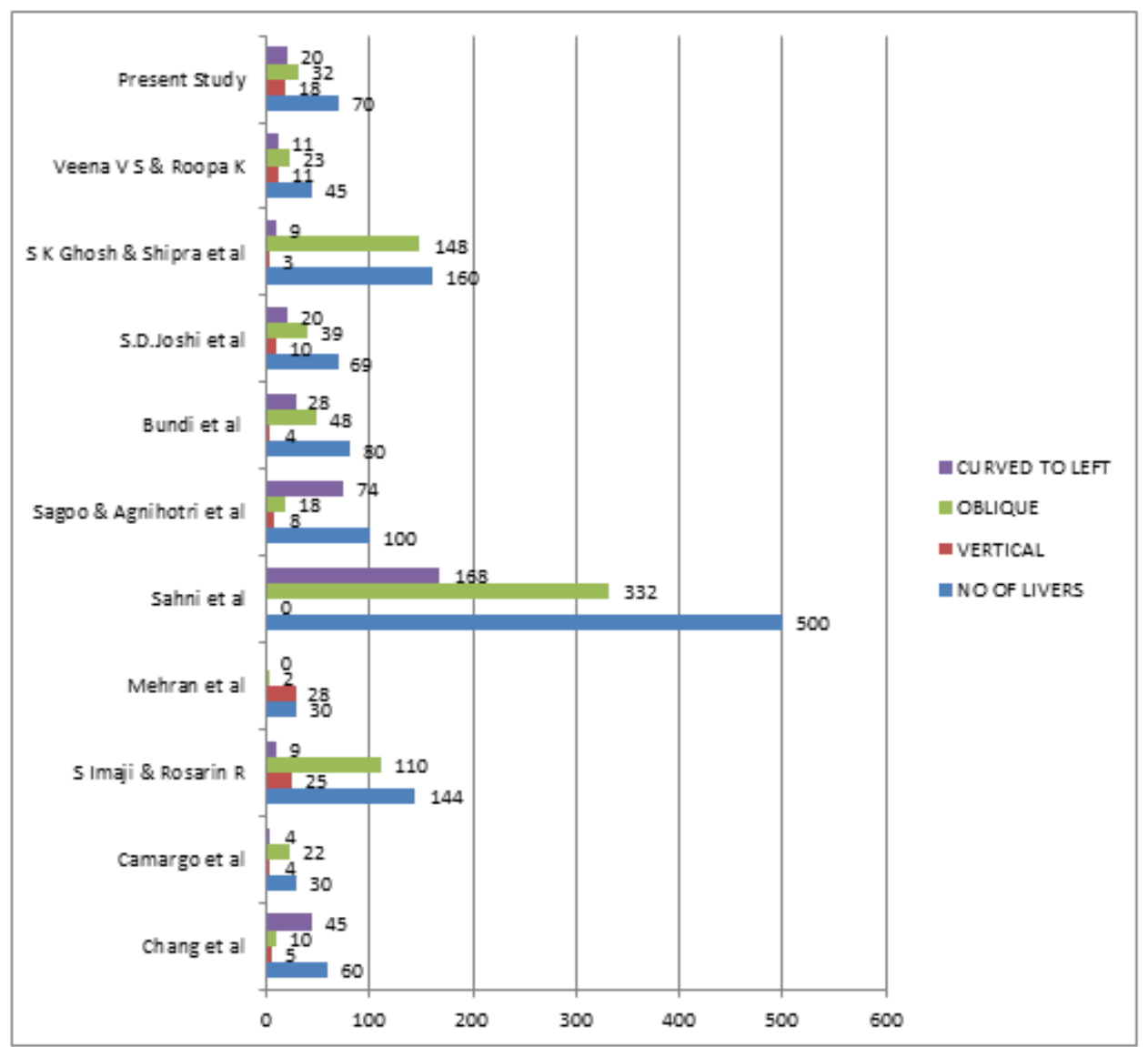

Fig-2: The cluster bar diagram shows the comparative measurements of the axial direction of RHIVC in the present vs. past studies using a horizontal rectangle

The oblique or curved orientation of the RHIVC means it was difficult to determine the direction of the centreline from the caudal side [12]. During the liver hanging manoeuvre, forceps were inserted through the centreline of the RHIVC. The slightly curved or oblique course allows an easy change in the direction of forceps. It was recommended that liver surgeons insert the forceps with a slight external twisting of the hand (leftward) along the non-vertical course of the RHIVC [12]. This was because the RHIVC makes a leftward shift from caudal to cranial ends [1] and there were very few venous obstacles in this course [13]. Studies have not explored the differences in this manoeuvre between right and lefthanded surgeons. However, the slight external twisting of the hand implies that the vein does not assume a vertical course through the liver, but takes an oblique course.

\section{CONCLUSION}

In this study, we obtained the gross morphological details about the axial direction of the retrohepatic segment of the inferior vena cava in the Tamilnadu population. Complete and thorough knowledge of the surgical vascular anatomy of the liver has become an important and integral component of donor harvesting as well as the recipient in vascular grafting, stenting and liver transplantation. So, prior knowledge about this segment and understanding of these morphological variations enlightens to avert us inadvertent traumas and unforeseen bleeding to a great extent. To conclude, this study re-emphasizes the vitality of the knowledge of the varied pattern of the axial direction of the retrohepatic segment of inferior vena cava in facilitating an accurate and better-designed road map for the hepatologists, liver transplant surgeons and interventional radiologists [14].

\section{REFERENCES}

1. Guo, L. K. (1981). Observations of channels through the liver in Chinese. Shaanxi Med. J, 10, 610.

2. Deshpande, R. R., Heaton, N. D., \& Rela, M. (2002). Surgical anatomy of segmental liver transplantation. British journal of surgery, 89(9), 1078-1088.

3. Chang, R. W., Shan-Quan, S., \& Yen, W. W. (1989). An applied anatomical study of the ostia venae hepaticae and the retrohepatic segment of the inferior vena cava. Journal of anatomy, 164, 41.

4. Sahni, D., Chawla, Y. K., \& Jit, I. (2006). Gross anatomy of the retrohepatic segment of the inferior vena cava in northwest Indians. Indian Journal of Medical Research, 124(1), 63. 
5. Gray, H., \& Standring, S. (2008). Gray's anatomy: the anatomical basis of clinical practice. Churchill Livingstone.

6. Camargo, A. M., Teixeira, G. G., \& Ortale, J. R. (1996). Anatomy of the ostia venae hepaticae and the retrohepatic segment of the inferior vena cava. Journal of anatomy, 188(Pt 1), 59.

7. Imjai, S., \& Ratnalekha, R. (1999). The ostia venae hepaticae and the rethrohepatic segments of the ivc in thais. J Med Assoc Thai, 82, 770-7.

8. Bundi, K. P., Ogeng'o, J. A., Hassanali, J., \& Odula, P. O. (2009). Course of the hepatic inferior vena cava in a Kenyan population. Clinical Anatomy: The Official Journal of the American Association of Clinical Anatomists and the British Association of Clinical Anatomists, 22(5), 610-613.

9. Ghosh, S. K., \& Paul, S. (2012). Anatomy of the retrohepatic segment of the inferior vena cava and the ostia venae hepaticae with its clinical significance. Surgical and radiologic anatomy, 34(4), 347-355.

10. Sagoo, M. G., \& Agnihotri, G. (2009). The retrohepatic segment of inferior vena cava and the ostia venae hepaticae in a Northwest Indian population. Braz J Morphol Sci, 26(3-4), 141-144.

11. Hirai, I., Murakami, G., Kimura, W., Kanamura, T., \& Sato, I. (2003). How should we treat short hepatic veins and paracaval branches in anterior hepatectomy using the hanging maneuver without mobilization of the liver? An anatomical and experimental study. Clinical Anatomy: The Official Journal of the American Association of Clinical Anatomists and the British Association of Clinical Anatomists, 16(3), 224-232.

12. Mehran, R., Schneider, R., \& Franchebois, P. (2000). The minor hepatic veins: anatomy and classification. Clinical Anatomy: The Official Journal of the American Association of Clinical Anatomists and the British Association of Clinical Anatomists, 13(6), 416-421.

13. Joshi, S. D., Joshi, S. S., \& Siddiqui, A. U. (2009). Anatomy of retrohepatic segment of inferior vena cava and termination of hepatic veins. Indian Journal of Gastroenterology, 28(6), 216-220. 